\title{
Implementation of new standard operating procedures for geriatric trauma patients with multiple injuries: a single level I trauma centre study
}

Lorenz Peterer', Christian Ossendorf', Kai Oliver Jensen'1, Georg Osterhoff', Ladislav Mica', Burkhardt Seifert ${ }^{2}$, Clément M. L. Werner ${ }^{1}$, Hans-Peter Simmen ${ }^{1}$, Hans-Christoph Pape ${ }^{1}$ and Kai Sprengel ${ }^{1 *}$ (D)

\begin{abstract}
Background: The demographic changes towards ageing of the populations in developed countries impose a challenge to trauma centres, as geriatric trauma patients require specific diagnostic and therapeutic procedures. This study investigated whether the integration of new standard operating procedures (SOPs) for the resuscitation room (ER) has an impact on the clinical course in geriatric patients. The new SOPs were designed for severely injured adult trauma patients, based on the Advanced Trauma Life Support (ATLS) and imply early whole-body computed tomography $(\mathrm{CT})$, damage control surgery, and the use of goal-directed coagulation management.
\end{abstract}

Methods: Single-centre cohort study. We included all patients $\geq 65$ years of age with an Injury Severity Score (ISS) $\geq 9$ who were admitted to our hospital primarily via ER. A historic cohort was compared to a cohort after the implementation of the new SOPs.

Results: We enrolled 311 patients who met the inclusion criteria between 2000 and 2006 (group PreSOP) and 2010-2012 (group SOP). There was a significant reduction in the mortality rate after the implementation of the new SOPs $(P=.001)$. This benefit was seen only for severely injured patients (ISS $\geq 16)$, but not for moderately injured patients (ISS 9-15). There were no differences with regard to infection rates or rate of palliative care.

Conclusions: We found an association between implementation of new ER SOPs, and a lower mortality rate in severely injured geriatric trauma patients, whereas moderately injured patients did not obtain the same benefit.

Trial registration: Clinicaltrials.gov NCT03319381, retrospectively registered 24 October 2017.

Keywords: Algorithm, Geriatrics, In-hospital mortality, Multiple trauma, Standard of care

\section{Background}

Populations continue to age in developed countries [1]. Switzerland exhibits the same demographic trends as other developed countries in Western Europe [2], where $18.1 \%$ of the Swiss population was aged $\geq 65$ years in 2016 , but people aged $>65$ years comprised only $11.5 \%$ of the population in 1970 [3]. People are living longer and maintain independent and active lifestyles; associated with a higher proportion of geriatric patients [4].

\footnotetext{
* Correspondence: kai.sprengel@usz.ch

${ }^{1}$ Department of Trauma, University Hospital Zurich, Raemistrasse 100, 8091

Zurich, Switzerland

Full list of author information is available at the end of the article
}

Age is known to be a significant risk factor for morbidity and mortality in trauma patients [5]. Several studies have demonstrated that geriatric trauma patients have worse outcomes if the severity of the injury is equivalent [610]. These poor outcomes are linked to a higher susceptibility to post-traumatic infections, decreased physiological reserves, and pre-existing diseases in elderly trauma patients $[11,12]$. This concept of frailty has only recently been recognized in surgical practice [13]. Anticoagulants make them more vulnerable to intracranial haemorrhage [14] and prolonged ventilatory support due to frailty is a risk factor for organ failure [15]. However, under-triage, a well-recognised phenomenon in geriatric 
trauma patients, might contribute to the poor outcome [16]. The American Geriatrics Society and John A. Hartford Foundation developed a research agenda to enhance the quality of care of geriatric patients including traumarelated questions [17]. We aimed to address the need for standardisation of definitions and evaluating the prognostic value of injury severity scores in improving outcomes in geriatric trauma patients.

The present study determined the outcomes for geriatric trauma patients aged over 65 years. In particular, we investigated whether there were changes in the in-hospital mortality, infection rate, and rate of palliative care (withdrawal of medical support) after the implementation of new standard operating procedures (SOPs) comprising early whole-body CT, damage control surgery, and the use of goal-directed coagulation management based on an Advanced Trauma Life Support (ATLS)-based algorithm. We included patients with an Injury Severity Score (ISS) $\geq 9$ in order to determine whether moderately and severely injured geriatric trauma patients benefited from the implementation of the new SOPs.

\section{Methods}

\section{Study design and patients}

This study involved the analysis of a prospective singlecentre database which bases upon the national trauma registry data of our single centre. The regional institutional review board approved this study (Kantonale Ethikkommision Zürich, Switzerland, StV-01/2008, 20.11.2007). The need for consent from patients was waived because the database was an anonymous registry. The present study was conducted in accordance with the principles of the Declaration of Helsinki and Good Clinical Practice Guidelines. Furthermore, this study adhered to the "STrengthening the Reporting of OBservational studies in Epidemiology" (STROBE) recommendations for cohort studies [18].

\section{Definitions}

The primary endpoint of the study was in-hospital mortality, defined as trauma related death during the hospital course. Infections and rate of palliative care were secondary outcome parameters. Criteria for infection varied depending on the site of infection. Pneumonia was diagnosed when a predominant organism was isolated from appropriately obtained sputum cultures in the setting of purulent sputum production and/or a new or changing pulmonary infiltrate on chest radiography. Bloodstream infections were diagnosed when the predominant organism was identified in blood cultures obtained under sterile conditions. Criteria for urinary tract infections (UTIs) included isolation of $>10^{5}$ organisms/ $\mathrm{ml}$ urine or $>10^{4}$ organisms in patients with symptoms typical for UTIs. Criteria for catheter-related infection included isolation of $>5$ colony forming units (CFU) from catheter tips cultured only in the setting of suspected infection. Postoperative surgical side infection was said to be present in case of incision drainage or the presence of an abscess with at least one positive culture, as well as any delay in wound healing that was treated by antibiotics or surgical revision.

Palliative care was defined of withdrawal of medical support. Withdrawal of medical support was initiated in nonsurvivable injuries or unconsciousness patients with severe traumatic brain injury (TBI) after neurosurgical consultation and obviously serious brain damage in whom a severely disabled outcome is anticipated. However, withdrawal of medical support was only initiated following consultation of close family members.

\section{Parameters of interest}

The recorded data comprised the age, gender, patient trauma load, and trauma sequelae according to the maximum injury severity on the Maximum Abbreviated Injury Scale 2005 Update 2008 (MAIS) for different body regions [19], ISS [20] and new ISS (NISS) [21], Glasgow Coma Scale (GCS) [22], base excess [23], lactate [24], haemoglobin [25], prothrombin (PT) [26], Acute Physiology and Chronic Health Evaluation (APACHE) II Score [27], and the Trauma and Injury Severity Score (TRISS) [28], where the latter was used to predict mortality. The standardized mortality ratio (SMR) was calculated as the observed mortality divided by the expected mortality.

\section{Group distribution}

In our hospital, we use a standardised clinical approach to trauma patients according to leading trauma guidelines based on ATLS [29]. The implemented SOPs have additionally included early whole-body CT scans and consequent application of damage control surgery principles since 2008 [30]. In the same year, the first version of a goal-directed transfusion protocol was introduced. In 2009, other changes in trauma management have also been made, including early administration of tranexamic acid, restrictive fluid resuscitation, and permissive hypotension. Therefore, in the years before (2000-2006), and the years after (2010-2012) the introduction and full implementation of these changes were chosen for analysis and verified by internal controls. Details, especially our goal-directed transfusion protocol algorithm, were described previously [30]. Patients admitted via ER with need for intensive care treatment after the ER phase were included and compared before the implementation of the new SOPs (group PreSOP; 1 January, 2000-31 December, 2006) and after their implementation in 2009 (group SOP, 1 January, 2010-31 December, 2012). The exclusion criteria comprised age $<65$ years, ISS $<9$, and transfers from other hospitals. 


\section{Statistical analysis}

Patients were classified into two groups according to the time period (group PreSOP; time period 2000-2006; group SOP; time period 2010-2012). Descriptive statistics were calculated to summarize the characteristics of the study population. The data were represented as the mean \pm standard deviation (SD) for continuous variables and as proportions for categorical variables. Person's chi-square, Fisher's exact and Mann-Whitney $U$ test were used to compare the treatments.

Binary logistic regression analysis was conducted to measure the strengths of associations and to identify possible risk factors related to mortality: time period, ISS group, PT group, age, and gender. The Hosmer-Lemeshow goodness-of-fit test were used to test the quality of the logistic models. All analyses were two-sided and a $P$-value < .05 was considered to indicate a significant difference. All statistical analyses were performed with SPSS software (version 23.0; IBM Corporation, Armonk, NY, USA). Graphical visualizations were prepared using Excel and Visio Professional 2016 (Microsoft, Redmond, WA, USA).

\section{Results}

In recent decades, more trauma patients have been hospitalized in our clinic and the proportion of patients aged $\geq 65$ years has increased (Fig. 1).
The characteristics and parameters for the patients are shown in Table 1 . We analysed 311 patients who met the inclusion criteria in this study, i.e., 131 between 2000 and 2006 in group PreSOP, and 180 between 2010 and 2012 in group SOP. There were significant differences between the cohorts in terms of age, lactate, APACHE II score, MAIS head or neck, MAIS abdomen, and MAIS external.

Using the ISS, patients were grouped into moderately (ISS $=9-15)$ and severely (ISS $\geq 16)$ injured subgroups. During 2000-2006 (group PreSOP), 14 patients were enrolled into the ISS $=9-15$ subgroup and 117 in the ISS $\geq$ 16 subgroup. Between 2010 and 2012 (group SOP), 34 patients were moderately injured and 146 were severely injured (Fig. 2).

Patients aged $\geq 65$ years were further divided into 65 79 years and $\geq 80$ years subgroups. Figure 3 shows the increase in the proportion of patients aged $\geq 80$ years during the study period.

In group PreSOP, 84/131 of the geriatric trauma patients died (64.1\%), 28 patients suffered from infections (21.4\%), and 31 patients (23.7\%) received palliative care. However, information about the withdrawal of medical support was missing for six patients. Among the 84 patients who died, four were moderately injured (ISS $=9$ 15 ) and 80 were severely injured (ISS $\geq 16$ ). Therefore,

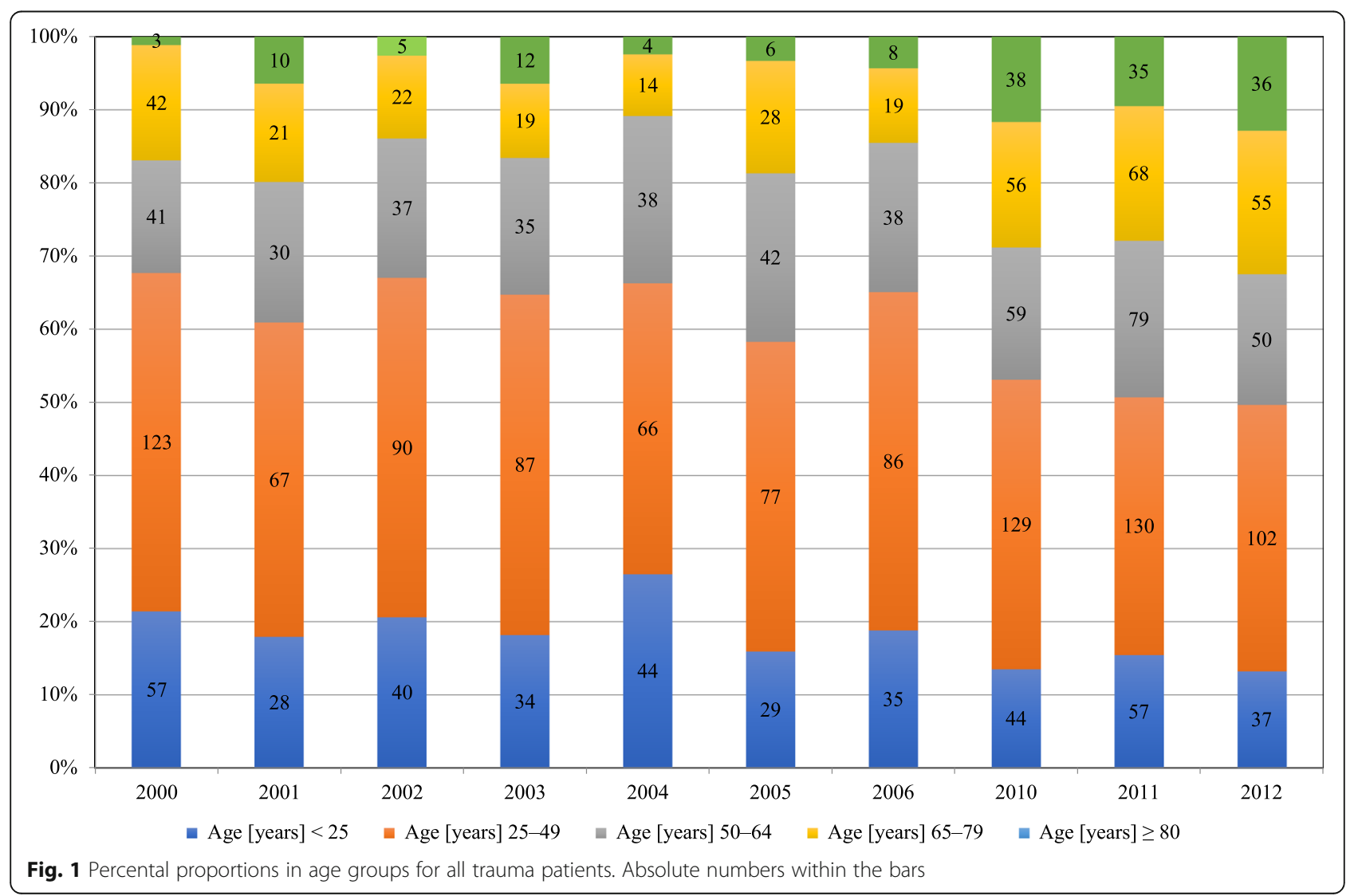


Table 1 Characteristics of patients in the two cohorts. Data represent the mean \pm standard deviation and numbers (proportions). APACHE: Acute Physiology and Chronic Health Evaluation; AP: arterial pressure; GCS: Glasgow Coma Scale; ISS: Injury Severity Score; MAIS: Maximum Abbreviated Injury Scale in this region; NISS: New ISS; TRISS: Trauma and Injury Severity Score

\begin{tabular}{|c|c|c|c|c|}
\hline Characteristics & $\begin{array}{l}\text { PreSOP } \\
(2000-2006)\end{array}$ & $\begin{array}{l}\text { SOP } \\
(2010-2012)\end{array}$ & Total & $P$-value \\
\hline N & 131 & 180 & 311 & \\
\hline Age [years] & $75 \pm 7$ & $77 \pm 8$ & $76 \pm 7$ & $.046^{*}$ \\
\hline Gender [\% male] & $59 \%$ & $59 \%$ & $59 \%$ & $.91^{\neq}$ \\
\hline MAIS head or neck & $3.02 \pm 2.07$ & $3.72 \pm 1.91$ & $3.43 \pm 2.00$ & $.032^{*}$ \\
\hline MAIS face & $0.45 \pm 0.94$ & $0.66 \pm 1.07$ & $0.57 \pm 1.02$ & $.16^{*}$ \\
\hline MAIS spine & $0.64 \pm 1.28$ & $0.64 \pm 1.20$ & $0.64 \pm 1.23$ & $.33^{*}$ \\
\hline MAIS chest & $1.75 \pm 1.76$ & $1.51 \pm 1.73$ & $1.61 \pm 1.74$ & $.28^{*}$ \\
\hline MAIS abdomen & $0.83 \pm 1.56$ & $0.37 \pm 0.98$ & $0.56 \pm 1.27$ & $.007^{*}$ \\
\hline MAIS pelvis & $0.71 \pm 1.29$ & $0.63 \pm 1.34$ & $0.66 \pm 1.32$ & $.48^{*}$ \\
\hline MAIS extremities & $1.36 \pm 1.49$ & $1.18 \pm 1.45$ & $1.25 \pm 1.47$ & $.69^{*}$ \\
\hline MAIS external & $0.36 \pm 0.63$ & $0.74 \pm 0.88$ & $0.59 \pm 0.81$ & $.008^{*}$ \\
\hline GCS & $7.31 \pm 5.32$ & $8.18 \pm 5.15$ & $7.81 \pm 5.23$ & $.39^{*}$ \\
\hline ISS & $29 \pm 12$ & $37 \pm 24$ & $34 \pm 20$ & $.28^{*}$ \\
\hline NISS & $42 \pm 17$ & $42 \pm 22$ & $42 \pm 20$ & $.41^{*}$ \\
\hline Mean AP [mmHg] & $93 \pm 25$ & $97 \pm 24$ & $96 \pm 24$ & $.25^{*}$ \\
\hline Base excess [mEq/L] & $-4.3 \pm 5.0$ & $-3.5 \pm 5.6$ & $-3.8 \pm 5.4$ & $.64^{*}$ \\
\hline Lactate $[\mathrm{mmol} / \mathrm{L}]$ & $3.5 \pm 2.8$ & $2.3 \pm 2.0$ & $2.8 \pm 2.5$ & $<.001^{*}$ \\
\hline Haemoglobin $[\mathrm{g} / \mathrm{L}]$ & $10.4 \pm 4.2$ & $11.6 \pm 7.8$ & $11.2 \pm 6.7$ & $.094^{*}$ \\
\hline Prothrombin [\% normal] & $76 \pm 24$ & $71 \pm 25$ & $72 \pm 25$ & $.072^{*}$ \\
\hline APACHE II score & $21 \pm 9$ & $18 \pm 8$ & $20 \pm 8$ & $.034^{*}$ \\
\hline TRISS & $0.71 \pm 0.28$ & $0.63 \pm 0.39$ & $0.66 \pm 0.35$ & $.72^{*}$ \\
\hline
\end{tabular}

* Mann-Whitney U test, ${ }^{\ddagger}$ Pearsons's chi-square

the mortality rate was $28.6 \%(n=4 / 14)$ in the ISS $=9-15$ subgroup. The mortality rate was more than twice as high in the ISS $\geq 16$ subgroup with a mortality rate of $68.4 \%(n=80 / 117)$. The infection rate in the ISS $=9-15$ subgroup was $7.1 \%(n=1 / 14)$ in group PreSOP. However, the infection rate in the ISS $\geq 16$ subgroup was $23.1 \%(n=27 / 117)$ in the same time period.

In group SOP, the mortality rate was significant lower (44.4\%; $n=80 / 180 ; P=.001)$ whereas the rate of infections $(21.9 \% ; n=39)$ and withdrawal of medical support $(28.3 \% ; n=51)$ was comparable and not significant different with group PreSOP. Among the 80 patients who died, again only seven belonged to the ISS $=9-15$ subgroup and the majority of 73 to the ISS $\geq 16$ subgroup as in group PreSOP. The mortality rate was with $20.6 \%$ $(n=7 / 34)$ lower but not significant in the ISS 9-15 subgroup $(P=.71)$. The mortality rate was again two and a half times higher at $50 \%(n=73 / 146)$ in the ISS $\geq 16$ subgroup and significant lower to group PreSOP $(P=.003)$. The infection rate was higher but not significant with $14.7 \%(n=5 / 34)$ in the ISS $=9-15$ subgroup in group SOP compared to group PreSOP and not significant similar in the ISS $\geq 16$ subgroup (23.6\%; $n=34 / 144)$.
Information about the infection status was missing for two patients.

The SMR was 0.90 in group PreSOP and 0.70 in Group SOP. Hence, the observed mortality rate was below the expected mortality rate in both study periods.

The mean PT in the 259 patients was $72.5 \%(\mathrm{SD}=$ $24.9 \%$, range $=10-136 \%$ ). The mortality rate was $80 \%$ $(n=8 / 10)$ in group PreSOP among patients with $\mathrm{PT} \leq$ $30 \%$, which probably indicated pre-existing anticoagulation medication. In group SOP, the mortality rate for patients with $\mathrm{PT} \leq 30 \%$ was $53.3 \%(n=8 / 15)$, which was not significant $(P=.23)$. There was a significant $(P=.002)$ lower mortality rate of patients with $\mathrm{PT}>30 \%$ from $60.5 \%(n=49 / 81)$ in group PreSOP to $39.2 \%$ ( $n=$ $60 / 153)$ in group SOP. In group PreSOP, $10 \%$ of the patients $(n=1 / 10)$ with $\mathrm{PT} \leq 30$ and $18.5 \%$ of the patients $(n=15 / 81)$ with $\mathrm{PT}>30 \%$ suffered from infections. In group SOP, $46.7 \%$ of the patients $(n=7 / 15)$ with $\mathrm{PT} \leq 30$ and $21.2 \%$ of the patients $(n=32 / 151)$ with $\mathrm{PT}>30 \%$ suffered from infections. Therefore, between the twotime periods, there was a not significant trend of increase in the infection rate among patients with $\mathrm{PT} \leq$ $30 \%$ (from 10.0 to $46.7 \%$; $P=.088$ ) but a not significant 


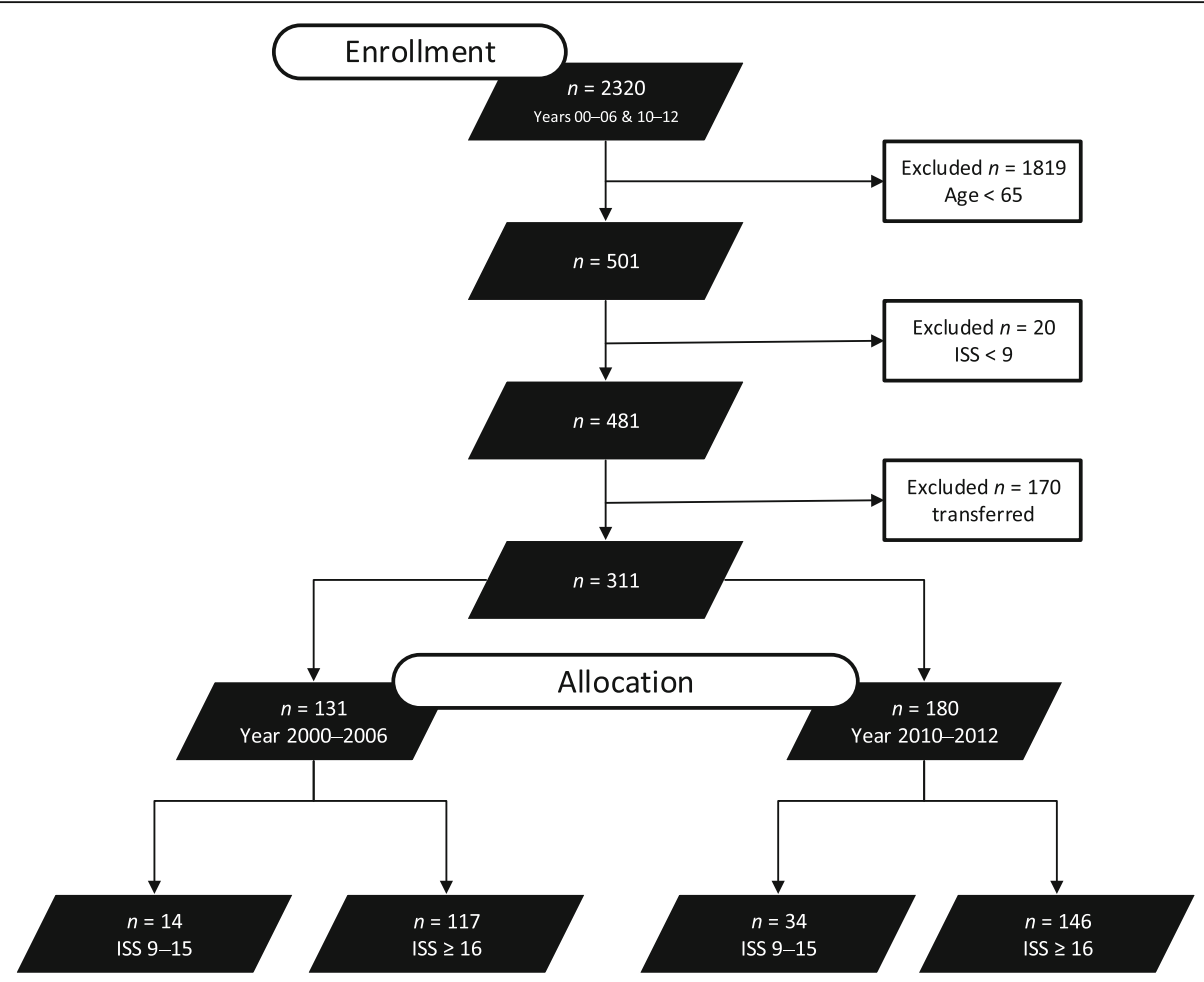

Fig. 2 Flow chart illustrating the patient inclusion and exclusion criteria

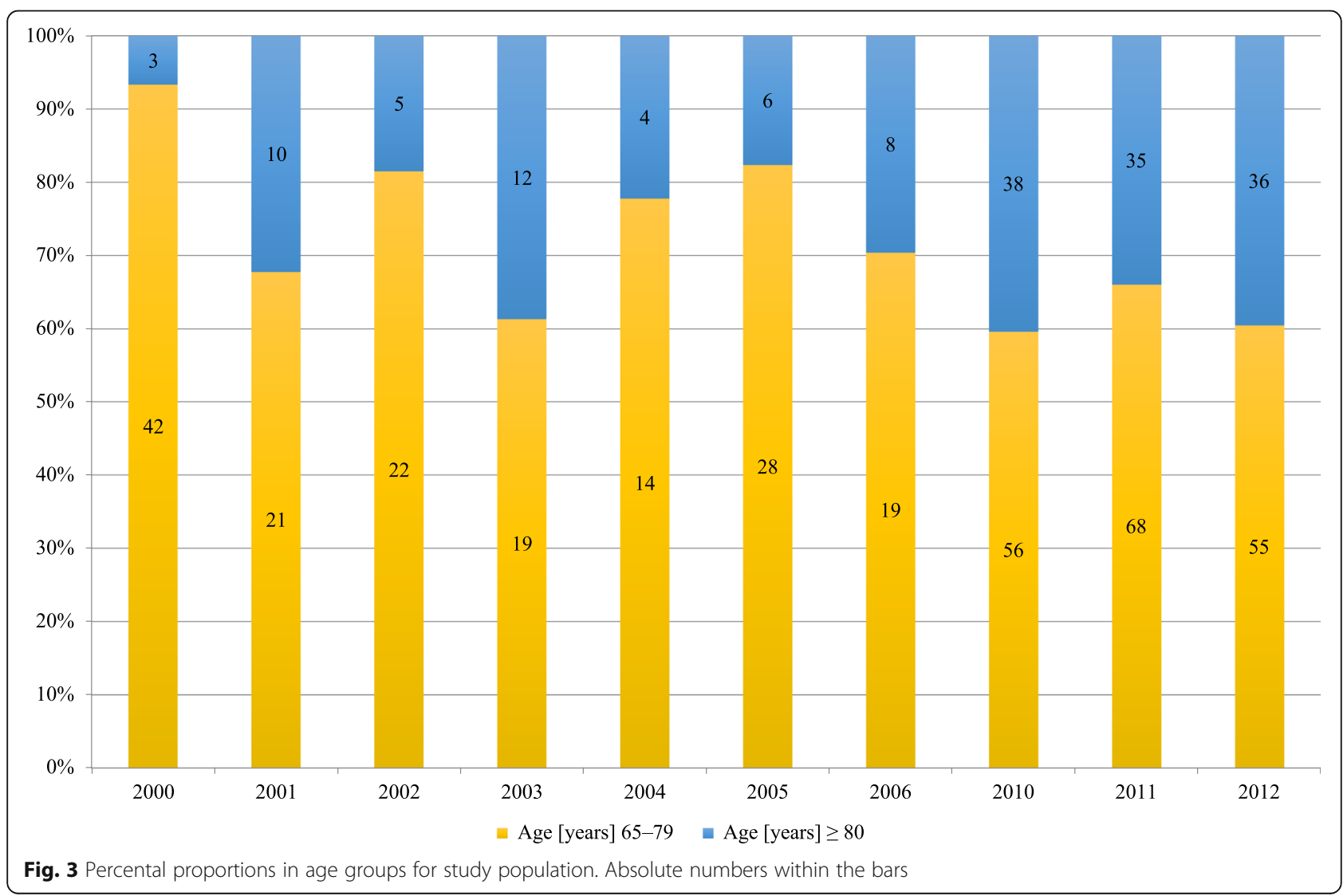




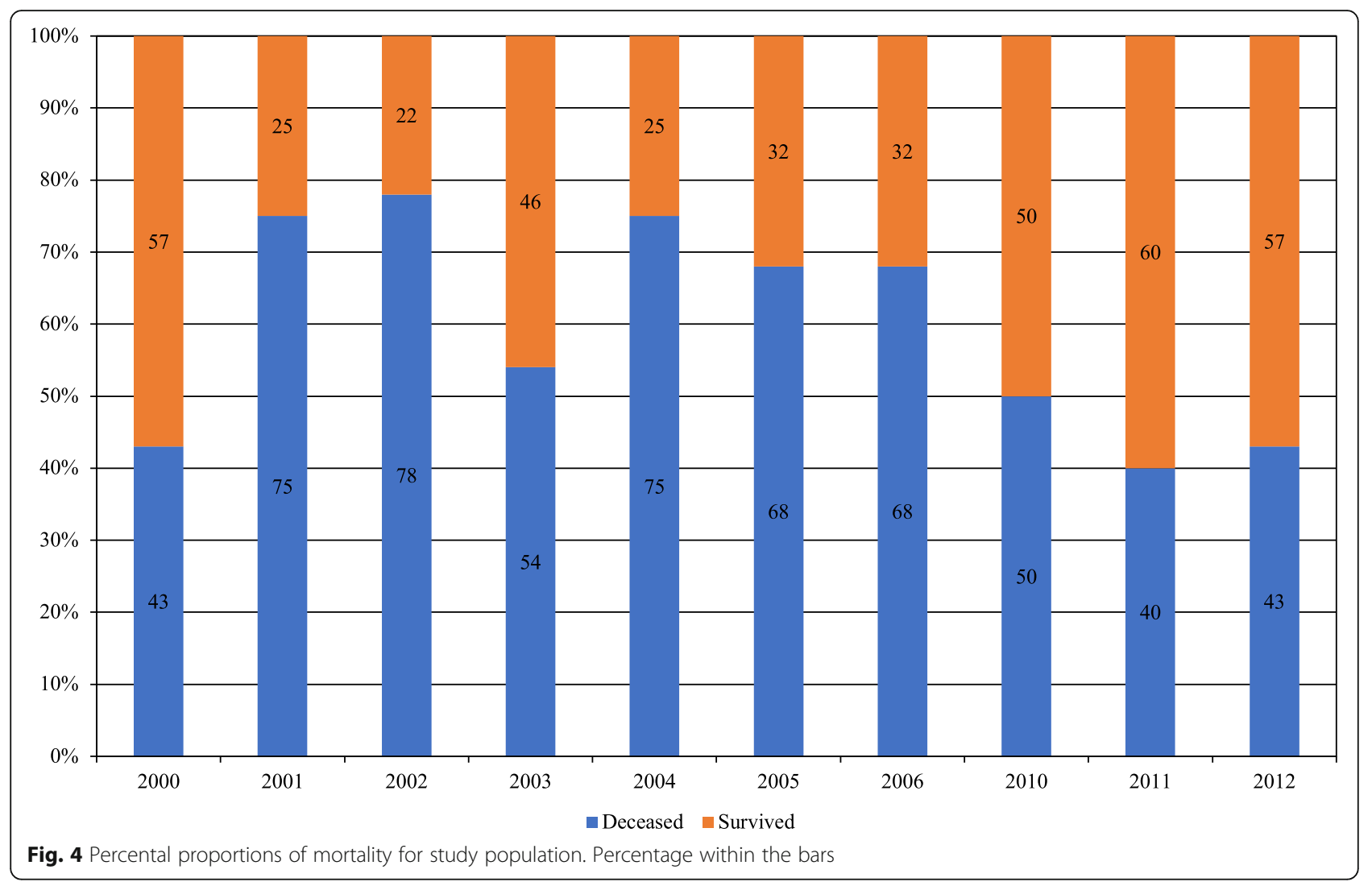

increase among patients with $\mathrm{PT}>30 \%$ (from 18.5 to $21.2 \% ; P=.63)$.

TBIs were the leading cause of death in both time periods $(60.2 \%$ of deaths in time group PreSOP and $72.5 \%$ of deaths in group SOP, respectively, which corresponded to a higher MAIS head or neck score in group SOP). However, the rate of exsanguinating patients decreased from $26.5 \%$ in group PreSOP to $7.5 \%$ in group SOP.

Table 2 shows the statistics for the mortality rate and infection rate.

Multivariate binary logistic regression indicated that time period, ISS group, and age were all independently associated with in-hospital death. PT group and gender were not associated with in-hospital death. The Hosmer-Lemeshow test (chi-square $=13.156, P=.11)$ indicated that the numbers of deaths were not significantly different from those predicted by the model, and thus the overall model fit was fair.

Multivariate binary logistic regression indicated that age was independently associated with infection, whereas time period, ISS group, PT group, and gender were not associated with infection. The Hosmer-Lemeshow test (chisquare $=3.685, P=.88)$ indicated that the numbers of infections were not significantly different from those predicted by the model, and thus the overall model fit was good. There was no obvious linear trend over time, neither for mortality nor for infection (Tables 3, 4 and Fig. 4).

\section{Discussion}

Integration of guidelines and SOPs have been shown to improve in the hospital course, and clinical outcome [31], including a lower rate of mortality and better clinical outcomes in severely injured patients [32,33]. The integration of whole-body CT scans into the early resuscitation phase for patients with major trauma has increased the probability of survival in several studies [34-36]. In contrast, the international, multicentre, randomised controlled

Table 2 Differences in mortality and infection rates between 2000 and 2006 (group PreSOP) and 2010-2012 (group SOP)

\begin{tabular}{|c|c|c|c|c|}
\hline Outcome & Subgroup & $\begin{array}{l}\text { PresOP } \\
{[\mathrm{n}] / \%}\end{array}$ & $\begin{array}{l}\text { SOP } \\
{[\mathrm{n}] / \%}\end{array}$ & $P$-value \\
\hline \multirow[t]{5}{*}{ Mortality rate } & ISS $=9-15$ & 4 / 28.6\% & 7 / 20.6\% & $.71^{*}$ \\
\hline & $I S S \geq 16$ & $80 / 68.4 \%$ & 73 / 50.0\% & $.003^{\ddagger}$ \\
\hline & Total & $84 / 64.1 \%$ & $80 / 44.4 \%$ & $.001^{\neq}$ \\
\hline & $\mathrm{PT} \leq 30 \%$ & $8 / 80.0 \%$ & $8 / 53.3 \%$ & $.23^{*}$ \\
\hline & PT > 30\% & 49 / 60.5\% & 60 / 39.2\% & $.002^{\ddagger}$ \\
\hline \multirow[t]{5}{*}{ Infection rate } & ISS $=9-15$ & 1 / 7.1\% & $5 / 14.7 \%$ & $.66^{*}$ \\
\hline & $I S S \geq 16$ & 27 / 23.1\% & 34 / 23.6\% & $.92^{\ddagger}$ \\
\hline & Total & $28 / 21.4 \%$ & 39 / 21.9\% & $.91^{\ddagger}$ \\
\hline & $\mathrm{PT} \leq 30 \%$ & $1 / 10.0 \%$ & 7 / 46.7\% & $.088^{*}$ \\
\hline & PT > 30\% & 15 / 18.5\% & 32 / 21.2\% & $.63^{\ddagger}$ \\
\hline
\end{tabular}

ISS Injury Severity Score, $P T$ prothrombin

*Fisher's exact, $\neq$ Pearsons's chi-square 
Table 3 Logistic regression model of mortality and infection rates. Time period 2000-2006 and 2010-2012, ISS: Injury Severity Score (grouped ISS 9-15 and ISS $\geq 16$ ); PT: prothrombin (grouped PT $>30 \%$ and $\leq 30 \%$ )

\begin{tabular}{|c|c|c|c|c|}
\hline Outcome & Parameter & Regression coefficient $\beta$ & $P$-value & $\begin{array}{l}\text { Odds ratio } \\
\left(e^{\beta} ; 95 \% \mathrm{Cl}\right)\end{array}$ \\
\hline \multirow[t]{5}{*}{ Mortality rate } & Time period & -1.05 & $<.001$ & $.35(.20-.62)$ \\
\hline & ISS group & 1.51 & $<.001$ & $4.54(2.05-10.08)$ \\
\hline & PT group & -.68 & .15 & $.51(.20-1.28)$ \\
\hline & Age [years] & .073 & $<.001$ & $1.08(1.04-1.12)$ \\
\hline & Gender & .442 & .12 & $1.56(0.89-2.72)$ \\
\hline \multirow[t]{5}{*}{ Infection rate } & Time period & 0.51 & .13 & $1.67(.86-3.26)$ \\
\hline & ISS group & 0.81 & .088 & $2.24(.89-5.68)$ \\
\hline & PT group & -.77 & .11 & $0.46(.18-1.17)$ \\
\hline & Age [years] & -.05 & .030 & $.95(.91-.96)$ \\
\hline & Gender & 1.49 & .86 & $.94(.50-1.79)$ \\
\hline
\end{tabular}

REACT-2 trial found no advantage of an immediate wholebody CT scans regarding in-hospital mortality, but there are some discussions about the weaknesses of this study, like a high number of not severely injured patient, a high dropout rate, or a high number of cross-overs from the

Table 4 The predictivity of time period for survival and infection by binary logistic regression with the possible confounders. With and without estimated linear trend over time. ISS: Injury Severity Score; Cl: confidence interval

\begin{tabular}{lllll}
\hline Parameter & Wald & $P$-value & Odds ratio & $95 \% \mathrm{Cl}$ \\
\hline a. Survival with estimated linear trend over time & & \\
Period & 6.730 & .009 & .325 & $.139-.760$ \\
ISS group & 15.990 & .000 & 4.604 & $2.178-9.732$ \\
Age [years] & 17.621 & .000 & 1.076 & $1.040-1.113$ \\
Trend & .290 & .590 & 1.045 & $.889-1.229$ \\
Constant & 15.292 & .000 & .002 &
\end{tabular}

b. Survival without estimated linear trend over time

$\begin{array}{lllll}\text { Period } & 13.331 & .000 & .392 & .237-.648 \\ \text { ISS group } & 16.038 & .000 & 4.613 & 2.183-9.748 \\ \text { Age [years] } & 17.645 & .000 & 1.075 & 1.040-1.113 \\ \text { Constant } & 19.440 & .000 & .001 & \end{array}$

c. Infection with estimated linear trend over time

$\begin{array}{lllll}\text { Period } & .516 & .472 & .716 & .288-1.781 \\ \text { ISS group } & 2.987 & .084 & 2.242 & .897-5.600 \\ \text { Age [years] } & 5.833 & .016 & .953 & .917-.991 \\ \text { Trend } & 1.891 & .169 & 1.140 & .946-1.373 \\ \text { Constant } & .603 & .437 & 4.201 & \end{array}$

d. Infection without estimated linear trend over time

\begin{tabular}{lllll} 
Period & .420 & .517 & 1.205 & $.686-2.115$ \\
ISS group & 2.997 & .083 & 2.240 & $.899-5.582$ \\
Age [years] & 5.727 & .017 & .954 & $.917-.991$ \\
Constant & .085 & .770 & 1.661 & \\
\hline
\end{tabular}

standard work-up group to the CT-group [37-39]. Especially the fact that many patients with a standard ATLSbased work-up will have a CT scan later could also be shown by our research group [40]. Furthermore, the use of a restricted volume replacement strategy during initial resuscitation has been proposed [41, 42]. In addition, the damage control approach has become the standard for the care of patients with multiple injuries [43-45].

In the present study, we explored the effects on the mortality and infection rates in geriatric trauma patients following the implementation of new ER SOPs. The main findings of this study were that the mortality rates decreased but the infection rates were unchanged after the implementation of the new SOPs. In addition, the mean age and mean ISS increased in the study population in recent years.

The synchronous implementation of different SOPs made it difficult to determine the individual impact of each. Other therapeutic changes might have occurred during hospital stays, which could have influenced the outcome parameters and we did not assess the long-term outcomes for the elderly trauma patients. We acknowledge that long-term outcome is an important measure in geriatric trauma care because in-hospital mortality underestimates post-discharge mortality; and trauma in the elderly affects long-term survival and health-care utilization [46-48]. However, there is growing evidence that interdisciplinary care of the hospitalised elderly trauma patient improves outcomes and reduces costs $[49,50]$. A single centre study from the United Kingdom showed a significant improvement in mortality and quality of care indicators after implementation of orthogeriatric care in patients with a hip fracture [51]. Good clinical outcomes in geriatric trauma patients are based upon several disciplines and the management in the resuscitation room is only one aspect of the recovery process. Continuity of care is especially important for these patients [52]. 
Patients with an ISS $=9-15$ might have been underrepresented because they were probably not triaged to the $\mathrm{ER}$, and thus were not included in the database. It is important to note that there were differences in the characteristics of the patients in our two study cohorts. In the Group SOP, the patients were slightly older, with higher MAIS head or neck and external, lower lactate on admission, lower APACHE II, and lower MAIS abdomen scores. The continuous increase in the age of trauma patients agrees with data obtained from the German Trauma Registry, which showed that there was an increase in patient age over recent decades [53], although the not significant tendency of increase in the ISS in our study did not agree with previous data. This difference is probably explained by the fact that we act as a referral centre for severe trauma, and especially for severe TBI, which was demonstrated by the increase in the MAIS head or neck score. In recent years in our country the medical care for these patients was more and more centralized.

The implementation of new SOPs into clinical practice is a complex and time-consuming process. This process was observed closely using written instructions and regular training sessions within our resuscitation team using simulation-based training and video review. Therefore, we think that our results are valid, because we chose an intermediate period of 4 years between both groups for implementation, which has been proofed in internal controls and some other studies of our research group [30]. Therefore, we can assure a strict implementation of the new SOPs in the Group SOP.

Our decrease in the mortality rate in geriatric trauma patients is consistent with the findings of Schoeneberg et al. who reported a similar reduction in mortality in severely injured patients (ISS $\geq 16$ ) after the introduction of evidence-based guidelines [33]. The higher probability of survival could be explained partly by a decrease in TRISS. However, the SMR decreased from group PreSOP to group SOP, although the SMR was below 1 in both time periods ( 0.90 and 0.70 , respectively), thereby indicating a better outcome than expected. In addition to severely injured trauma patients (ISS $\geq 16$ ) who have been investigated in many previous studies, we included moderately injured patients (ISS $=9-15$ ) in order to assess this underrepresented patient group. For a geriatric trauma patient, an ISS $\geq 9$ may represent severe trauma, as for example a hip fracture has an ISS of 9. However, literature on low level falls and this population of moderately injured geriatric trauma patients is limited $[6,54]$. In our study, patients with an ISS $\geq 16$ showed a decrease in mortality rate after implementation of the new SOPs, but the decrease in the mortality rate was not significant for patients with an ISS $=9-15$. The reasons for this difference are unclear, but we consider that in this moderately injured patient group, survival may have depended on factors other than the implementation of the new SOPs comprising early whole-body CT, damage control surgery, and goaldirected coagulation management. The new SOPs aimed to facilitate the prompt detection of all injuries, especially haemorrhage. Minor TBIs, non-displaced rib, or pelvic fractures can often be detected in elderly trauma patients, and more research is needed to improve the survival rates of these patients.

The mortality rates determined for geriatric trauma patients in the present study are higher than those reported in other studies $[10,53,55,56]$. It should be noted that there are significant differences in geriatric trauma outcomes between trauma centres [57-59]. However, our hospital acts as a referral centre for severe trauma and TBI, and thus the injury severity in our patients might have been higher than that in other study populations. The overall mean ISS of $34( \pm 20)$ reflects the injury severity in our study population. Furthermore, we did not exclude patients for whom medical support was withdrawn. In both time periods, the rate of palliative care was around $25 \%$. In addition, the age threshold that should be used to define elderly trauma patients is still controversial [60]. Thus, setting the age cut-off at different levels might have changed the mortality rates in the subgroups. We selected 65 years as the age threshold for geriatric trauma patients because of several reasons. First, large study cohorts have used the same threshold, which facilitates comparisons with other studies [7, 9, 55]. Furthermore, many epidemiological studies have employed an age cut-off of 65 years in Switzerland because it is the current retirement age. Thus, we consider that 65 years is a practical cut-off age for geriatric trauma patients.

The patients in our study cohort with PT > 30\% exhibited a marked increase in their probability of survival after the implementation of the new SOPs. Stein et al. also found that the 24-h and in-hospital mortality decreased significantly after the implementation of goaldirected coagulation management [30], although they noted that their study lacked sufficient power to assess this endpoint. It is not clear why the mortality rate of patients with $\mathrm{PT} \leq 30 \%$ did not improve in the same manner in our study, but we assume that patients with $\mathrm{PT} \leq 30 \%$ (which probably indicates anticoagulation medication) were already being treated aggressively before the implementation of goal-directed coagulation management because of known pre-existing anticoagulation medication. However, patients with $\mathrm{PT} \leq 30 \%$ did not appear to have significantly worse outcomes.

In our study, the infection rate did not change after the implementation of the new SOPs despite a tendency of a higher infection rate in patients with a $\mathrm{PT} \leq 30 \%$. It is well known that the immune system function of geriatric trauma patients is impaired and they are highly susceptible to infections [11]. Bochicchio et al. reported that age 
increased the risk of nosocomial infections in trauma patients aged $\geq 65$ years, who had a significantly higher mortality compared with younger patients, whereas respiratory infections were the most common followed by genitourinary infections in their study [61]. These results are consistent with our findings where pneumonia was the most common infection. However, in a multicentre cohort study, Blot et al. showed that ventilator-associated pneumonia did not occur more frequently among the elderly, although the associated mortality was higher in these patients [62]. In a review, Hazeldine et al. demonstrated that age-related changes in immune function may contribute to poor outcomes for geriatric trauma patients [63]. Therefore, further research is required to prevent infections and improve the outcomes for infected geriatric trauma patients.

This study had several limitations and strengths. It was based on a retrospective review of a prospectively collected single-centre trauma database. Registry data must be taken with caution as they only can show association and not cause-effect relationships. However, our data was collected and analysed by well-instructed personnel with an internal and external quality control. This was done one the one hand by the senior author in case of coding questions and reviewing all cases personally and on the other hand by the national trauma registry by its structure with quality control algorithms. Because of the singlecentre design, the results are only applicable to our trauma centre. It was a database investigation with a prospective data collection not specifically selected for this study, which allows the possibility of bias from unmeasured confounders associated with comorbidities and frailty. Undetected confounding factors, such as changes in prehospital treatment, may exist and must be considered when interpreting our results. Using smaller time increments could reduce the impact of undetected confounding factors. However, smaller time increments would reduce the number of patients and therefore the statistical power and increase failure to detect secular trends. Furthermore, we used in-hospital mortality as our end marker without any follow up data.

\section{Conclusions}

Our main findings suggest that the implementation of new SOPs comprising early whole-body CT, damage control surgery, and the use of goal-directed coagulation management significantly reduced the mortality rate in severely injured geriatric trauma patients, whereas moderately injured patients seemed not obtain the same benefit and with no influence on the infection rate. Further research is needed to improve the outcomes for this fast-growing population.

\section{Abbreviations}

AIS: Abbreviated Injury Scale; APACHE: Acute Physiology and Chronic Health Evaluation; ATLS: Advanced Trauma Life Support; CT: Computed tomography;
ER: Resuscitation room; GCS: Glasgow Coma Scale; ISS: Injury Severity Score; MAIS: Maximum Abbreviated Injury Scale; NISS: New Injury Severity Score; PT: Prothrombin; SD: Standard deviation; SMR: Standardized mortality ratio; SOP: Standard operating procedure; TBI: Traumatic brain injury; TRISS: Trauma and Injury Severity Score

\section{Acknowledgments}

The work presented in this paper has been presented in March 2018 at the 4th Geriatric Trauma Congress in Zürich, Switzerland; in May 2018 at the 105th Annual Congress of the Swiss Society of Surgery in Basel, Switzerland and the 19th European Congress of Trauma and Emergency Surgery, Valencia, Spain; in September 2018 at the 77th Annual Meeting of the American Association for the Surgery of Trauma and Clinical Congress of Acute Care Surgery \& 4th World Trauma Congress, San Diego (CA), USA; in October 2018 at the Orthopaedic Trauma Association Annual Meeting 2018 in Kissimmee Orlando (FL), USA and the German Congress of Orthopaedics and Traumatology 2018, Berlin, Germany. Abstracts of these presentations has been published in Swiss Knife [64] and the European Journal of Trauma and Emergency Surgery [65].

\section{Authors' contributions}

LP participated in the data collection, statistical analysis, and interpretation of data, and is the primary author of the manuscript. BS and KS conducted the statistical analysis. CO, KJ, GO, LM, CW, HPS, and HCP made substantial contributions to the conception of the study, research design, and interpretation of the data. KS supervised all phases of the study and revised the manuscript. All authors contributed to the writing and review of the manuscript and approved the final version.

\section{Funding}

Not applicable.

\section{Availability of data and materials}

All data of this submission are available from the Dryad Digital Repository, please consider the following link: https://doi.org/10.5061/dryad.2v6wwpzhk

\section{Ethics approval and consent to participate}

The regional institutional review board (Kantonale Ethikkommision Zürich, Switzerland, StV-01/2008, 20.11.2007) approved this study. The need for consent from patients was waived because the database was an anonymous registry.

\section{Consent for publication}

Not applicable.

\section{Competing interests}

The authors declare that they have no competing interests.

\section{Author details}

${ }^{1}$ Department of Trauma, University Hospital Zurich, Raemistrasse 100, 8091 Zurich, Switzerland. ${ }^{2}$ Department of Biostatistics at Epidemiology, Biostatistics and Prevention Institute, University of Zurich, Hirschengraben 84, 8001 Zurich, Switzerland.

Received: 12 November 2017 Accepted: 10 December 2019 Published online: 19 December 2019

\section{References}

1. McNicoll G. World Population Ageing: 1950-2050. New York: United Nations Population Division; 2001.

2. Population structure and ageing [http://ec.europa.eu/eurostat/statisticsexplained/index.php/Population_structure_and_ageing]. Accessed 4 July 2017.

3. Übersicht [http://www.bfs.admin.ch/bfs/portal/de/index/themen/01/02/ blank/key/bevoelkerungsstand.html]. Accessed 4 July 2017.

4. Kehoe A, Smith JE, Edwards A, Yates D, Lecky F. The changing face of major trauma in the UK. Emerg Med J. 2015:32:911-5.

5. Goodmanson NW, Rosengart MR, Barnato AE, Sperry JL, Peitzman AB, Marshall GT. Defining geriatric trauma: when does age make a difference? Surgery. 2012;152:668-74 discussion 674-665. 
6. Finelli FC, Jonsson J, Champion HR, Morelli S, Fouty WJ. A case control study for major trauma in geriatric patients. J Trauma. 1989;29:541-8.

7. Champion HR, Copes WS, Buyer D, Flanagan ME, Bain L, Sacco WJ. Major trauma in geriatric patients. Am J Public Health. 1989;79:1278-82.

8. Perdue PW, Watts DD, Kaufmann CR, Trask AL. Differences in mortality between elderly and younger adult trauma patients: geriatric status increases risk of delayed death. J Trauma. 1998:45:805-10.

9. Taylor MD, Tracy JK, Meyer W, Pasquale M, Napolitano LM. Trauma in the elderly: intensive care unit resource use and outcome. J Trauma. 2002;53:407-14.

10. Vanzant EL, Hilton RE, Lopez CM, Zhang J, Ungaro RF, Gentile LF, Szpila BE, Maier RV, Cuschieri J, Bihorac A, et al. Advanced age is associated with worsened outcomes and a unique genomic response in severely injured patients with hemorrhagic shock. Crit Care. 2015;19:77.

11. Butcher SK, Killampalli V, Chahal H, Kaya Alpar E, Lord JM. Effect of age on susceptibility to post-traumatic infection in the elderly. Biochem Soc Trans. 2003:31:449-51.

12. McMahon DJ, Schwab CW, Kauder D. Comorbidity and the elderly trauma patient. World J Surg. 1996;20:1113-9 discussion 1119-1120.

13. Robinson TN, Walston JD, Brummel NE, Deiner S, Brown CH, Kennedy M, Hurria A. Frailty for surgeons: review of a National Institute on Aging conference on frailty for specialists. J Am Coll Surg. 2015;221:1083-92.

14. Boltz MM, Podany AB, Hollenbeak CS, Armen SB. Injuries and outcomes associated with traumatic falls in the elderly population on oral anticoagulant therapy. Injury. 2015;46:1765-71.

15. Dasgupta M, Rolfson DB, Stolee P, Borrie MJ, Speechley M. Frailty is associated with postoperative complications in older adults with medical problems. Arch Gerontol Geriatr. 2009;48:78-83.

16. Lehmann R, Beekley A, Casey L, Salim A, Martin M. The impact of advanced age on trauma triage decisions and outcomes: a statewide analysis. Am J Surg. 2009;197:571-4 discussion 574-575.

17. New Frontiers in Geriatrics Research: An Agenda for Surgical and Related Medical Specialties [http://newfrontiers.americangeriatrics.org]. Accessed 4 July 2017.

18. STROBE Statement [https://www.strobe-statement.org/index.php?id= available-checklists]. Accessed 4 July 2017.

19. Gennarelli TAWE, Champion HR, MacKenzie EJ, Segui-Gomez M, Augenstein J, Civil I, Cushing B, Esposito T, Mackay M. Abbreviated Injury Scale 2005. Update 2008. Barrington: Association for the Advancement of Automotive Medicine; 2008.

20. Baker SP, O'Neill B, Haddon W, Long WB. The injury severity score: a method for describing patients with multiple injuries and evaluating emergency care. J Trauma. 1974;14:187-96.

21. Osler T, Baker SP, Long W. A modification of the injury severity score that both improves accuracy and simplifies scoring. J Trauma. 1997;43:922-5 discussion 925-926.

22. Teasdale G, Jennett B. Assessment of coma and impaired consciousness. A practical scale. Lancet. 1974;2:81-4.

23. Callaway DW, Shapiro NI, Donnino MW, Baker C, Rosen CL. Serum lactate and base deficit as predictors of mortality in normotensive elderly blunt trauma patients. J Trauma. 2009:66:1040-4.

24. Salottolo KM, Mains CW, Offner PJ, Bourg PW, Bar-Or D. A retrospective analysis of geriatric trauma patients: venous lactate is a better predictor of mortality than traditional vital signs. Scand J Trauma Resusc Emerg Med. 2013;21:7.

25. Braun BJ, Holstein J, Fritz T, Veith NT, Herath S, Mörsdorf P, Pohlemann T. Polytrauma in the elderly: a review. EFORT Open Rev. 2016;1:146-51.

26. Coleman J, Baldawi M, Heidt D. The effect anticoagulation status on geriatric fall trauma patients. Am J Surg. 2016;212:1237-42.

27. Knaus WA, Draper EA, Wagner DP, Zimmerman JE. APACHE II: a severity of disease classification system. Crit Care Med. 1985;13:818-29.

28. Boyd CR, Tolson MA, Copes WS. Evaluating trauma care: the TRISS method. Trauma score and the injury severity score. J Trauma. 1987;27:370-8.

29. Advanced Trauma Life Support (ATLS) Student Course Manual. Ninth Edition. Chicago: American College of Surgeon; 2012.

30. Stein P, Kaserer A, Sprengel K, Wanner GA, Seifert B, Theusinger OM, Spahn DR: Change of transfusion and treatment paradigm in major trauma patients. Anaesthesia 2017;72:1317-1326.

31. Grimshaw JM, Russell IT. Effect of clinical guidelines on medical practice: a systematic review of rigorous evaluations. Lancet. 1993;342:1317-22.

32. Rice TW, Morris S, Tortella BJ, Wheeler AP, Christensen MC. Deviations from evidence-based clinical management guidelines increase mortality in critically injured trauma patients*. Crit Care Med. 2012;40:778-86.
33. Schoeneberg C, Schilling M, Burggraf M, Fochtmann U, Lendemans S. Reduction in mortality in severely injured patients following the introduction of the "treatment of patients with severe and multiple injuries" guideline of the German society of trauma surgery--a retrospective analysis of a level 1 trauma center (2010-2012). Injury. 2014:45:635-8.

34. Huber-Wagner S, Lefering R, Qvick LM, Körner M, Kay MV, Pfeifer KJ, Reiser M, Mutschler W, Kanz KG. Society WGoPotGT: effect of whole-body $\subset$ during trauma resuscitation on sunvival: a retrospective, multicentre study. Lancet. 2009;373:1455-61.

35. Jiang $L$, Ma Y, Jiang $S$, Ye L, Zheng Z, Xu Y, Zhang M. Comparison of wholebody computed tomography vs selective radiological imaging on outcomes in major trauma patients: a meta-analysis. Scand J Trauma Resusc Emerg Med. 2014;22:54.

36. Huber-Wagner $S$, Biberthaler $P$, Häberle $S$, Wierer M, Dobritz M, Rummeny $E$, van Griensven M, Kanz KG, Lefering R, DGU T. Whole-body CT in haemodynamically unstable severely injured patients--a retrospective, multicentre study. PLoS One. 2013;8:e68880.

37. Sierink JC, Treskes K, Edwards MJ, Beuker BJ, den Hartog D, Hohmann J, Dijkgraaf MG, Luitse JS, Beenen LF, Hollmann MW, et al. Immediate totalbody CT scanning versus conventional imaging and selective CT scanning in patients with severe trauma (REACT-2): a randomised controlled trial. Lancet. 2016;388:673-83.

38. Huber-Wagner S, Lefering R, Kanz KG, Biberthaler P, Stengel D. The importance of immediate total-body CT scanning. Lancet. 2017;389:502-3.

39. Wurmb TE, Bernhard M. Total-body CT for initial diagnosis of severe trauma. Lancet. 2016;388:636-8.

40. Gordic S, Alkadhi H, Hodel S, Simmen HP, Brueesch M, Frauenfelder T, Wanner GA, Sprengel K. Whole-body CT-based imaging algorithm for multiple trauma patients: radiation dose and time to diagnosis. Br J Radiol. 2015;88:20140616.

41. Rossaint R, Bouillon B, Cerny V, Coats TJ, Duranteau J, Fernández-Mondéjar E, Filipescu D, Hunt BJ, Komadina R, Nardi G, et al. The European guideline on management of major bleeding and coagulopathy following trauma: fourth edition. Crit Care. 2016;20:100.

42. Spahn DR, Spahn GH, Stein P. Evidence base for restrictive transfusion triggers in high-risk patients. Transfus Med Hemother. 2015;42:110-4.

43. Rotondo MF, Schwab CW, McGonigal MD, Phillips GR, Fruchterman TM, Kauder DR, Latenser BA, Angood PA. 'Damage control': an approach for improved survival in exsanguinating penetrating abdominal injury. J Trauma. 1993;35:375-82 discussion 382-373.

44. Taeger G, Ruchholtz S, Waydhas C, Lewan U, Schmidt B, Nast-Kolb D. Damage control orthopedics in patients with multiple injuries is effective, time saving, and safe. J Trauma. 2005:59:409-16 discussion 417.

45. Pape HC, Tornetta P, Tarkin I, Tzioupis C, Sabeson V, Olson SA. Timing of fracture fixation in multitrauma patients: the role of early total care and damage control surgery. J Am Acad Orthop Surg. 2009;17:541-9.

46. Gubler KD, Davis R, Koepsell T, Soderberg R, Maier RV, Rivara FP. Long-term survival of elderly trauma patients. Arch Surg. 1997;132:1010-4.

47. Fleischman RJ, Adams AL, Hedges JR, Ma OJ, Mullins RJ, Newgard CD. The optimum follow-up period for assessing mortality outcomes in injured older adults. J Am Geriatr Soc. 2010;58:1843-9.

48. Wong TH, Nadkarni NV, Nguyen HV, Lim GH, Matchar DB, Seow DCC, King NKK, Ong MEH. One-year and three-year mortality prediction in adult major blunt trauma survivors: a National Retrospective Cohort Analysis. Scand J Trauma Resusc Emerg Med. 2018;26:28.

49. Kozar RA, Arbabi S, Stein DM, Shackford SR, Barraco RD, Biffl WL, Brasel KJ, Cooper Z, Fakhry SM, Livingston D, et al. Injury in the aged: geriatric trauma care at the crossroads. J Trauma Acute Care Surg. 2015;78:1197-209.

50. Olufajo OA, Tulebaev S, Javedan H, Gates J, Wang J, Duarte M, Kelly E, Lilley E, Salim A, Cooper Z. Integrating geriatric consults into routine Care of Older Trauma Patients: one-year experience of a level I trauma center. J Am Coll Surg. 2016;222:1029-35.

51. Middleton M, Wan B, da Assunçao R. Improving hip fracture outcomes with integrated orthogeriatric care: a comparison between two accepted orthogeriatric models. Age Ageing. 2017:46:465-70.

52. Havens JM, Olufajo OA, Tsai TC, Jiang W, Columbus AB, Nitzschke SL, Cooper Z, Salim A. Hospital factors associated with care discontinuity following emergency general surgery. JAMA Surg. 2017;152:242-9.

53. $\mathrm{DGU}\left({ }^{\bullet}\right) \mathrm{T} .20$ years of trauma documentation in Germany--actual trends and developments. Injury. 2014;45(Suppl 3):S14-9.

54. Helling TS, Watkins M, Evans LL, Nelson PW, Shook JW, Van Way CW. Low falls: an underappreciated mechanism of injury. J Trauma. 1999;46:453-6. 
55. Richmond TS, Kauder D, Strumpf N, Meredith T. Characteristics and outcomes of serious traumatic injury in older adults. J Am Geriatr Soc. 2002; 50:215-22.

56. Schönenberger A, Billeter AT, Seifert B, Neuhaus V, Trentz O, Turina M. Opportunities for improved trauma care of the elderly - a single center analysis of 2090 severely injured patients. Arch Gerontol Geriatr. 2012;55:660-6.

57. Matsushima K, Schaefer EW, Won EJ, Armen SB, Indeck MC, Soybel DI. Positive and negative volume-outcome relationships in the geriatric trauma population. JAMA Surg. 2014;149:319-26.

58. Zafar SN, Obirieze A, Schneider EB, Hashmi ZG, Scott VK, Greene WR, Efron DT, Mackenzie EJ, Cornwell EE, Haider AH. Outcomes of trauma care at centers treating a higher proportion of older patients: the case for geriatric trauma centers. J Trauma Acute Care Surg. 2015;78:852-9.

59. Olufajo OA, Metcalfe D, Rios-Diaz A, Lilley E, Havens JM, Kelly E, Weissman JS, Haider AH, Salim A, Cooper Z. Does Hospital Experience Rather than Volume Improve Outcomes in Geriatric Trauma Patients? J Am Coll Surg. 2016;223:32-40.e31.

60. Caterino JM, Valasek T, Werman HA. Identification of an age cutoff for increased mortality in patients with elderly trauma. Am J Emerg Med. 2010;28:151-8.

61. Bochicchio GV, Joshi M, Knorr KM, Scalea TM. Impact of nosocomial infections in trauma: does age make a difference? J Trauma. 2001;50:612-7 discussion 617-619.

62. Blot S, Koulenti D, Dimopoulos G, Martin C, Komnos A, Krueger WA, Spina G, Armaganidis A, Rello J, Investigators E-VS. Prevalence, risk factors, and mortality for ventilator-associated pneumonia in middle-aged, old, and very old critically ill patients*. Crit Care Med. 2014;42:601-9.

63. Hazeldine J, Lord JM, Hampson P. Immunesenescence and inflammaging: a contributory factor in the poor outcome of the geriatric trauma patient Ageing Res Rev. 2015;24:349-57.

64. Abstracts 105. Jahreskongress der Schweizerischen Gesellschaft für Chirurgie. Swiss Knife. 2018;15(Special Edition):52.

65. ECTES. Abstracts 2018. Eur J Trauma Emerg Surg. 2018:44(Suppl 2):430-1.

\section{Publisher's Note}

Springer Nature remains neutral with regard to jurisdictional claims in published maps and institutional affiliations.

Ready to submit your research? Choose BMC and benefit from:

- fast, convenient online submission

- thorough peer review by experienced researchers in your field

- rapid publication on acceptance

- support for research data, including large and complex data types

- gold Open Access which fosters wider collaboration and increased citations

- maximum visibility for your research: over $100 \mathrm{M}$ website views per year

At $\mathrm{BMC}$, research is always in progress.

Learn more biomedcentral.com/submissions 